
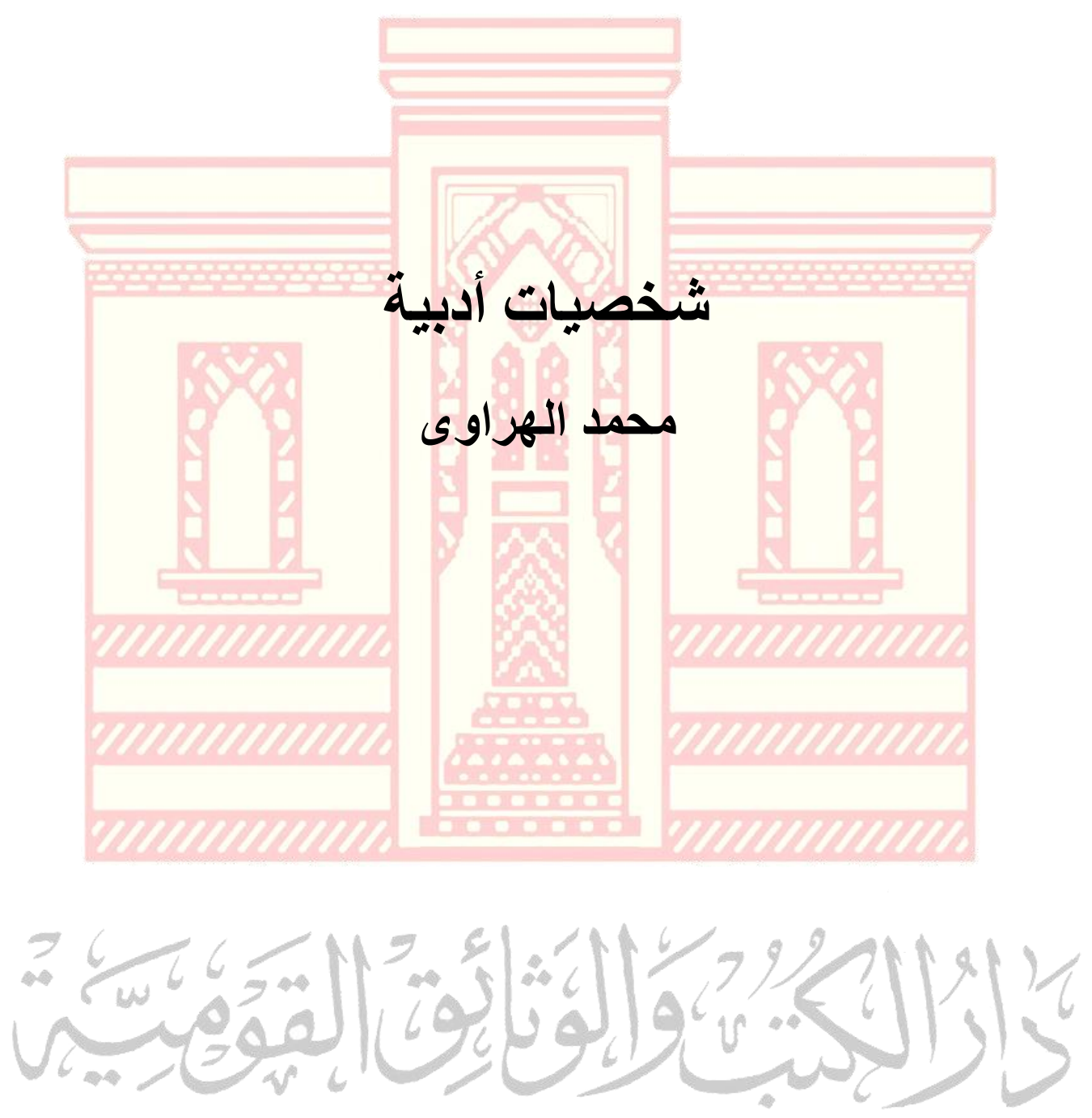


\section{محمد اللهراوى}

\section{شاعر الأطفال}

$\left.\left(b^{\prime} q \mu q-5\right) \wedge \wedge 0\right)$

أ.مها حسنين سليمان

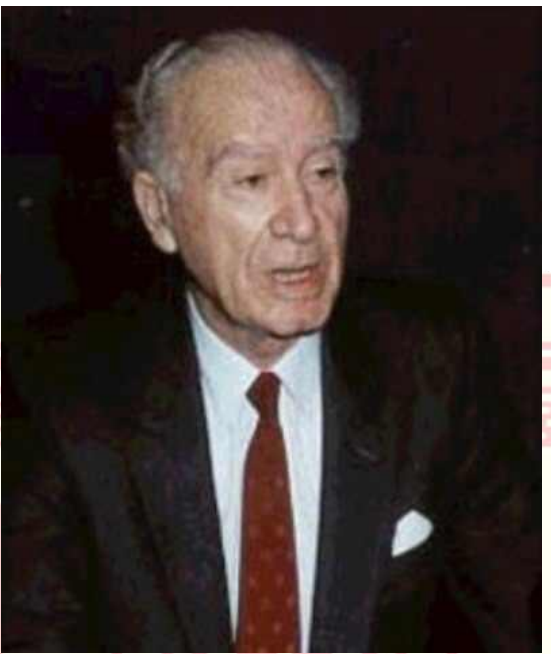

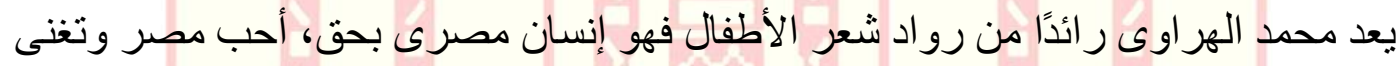

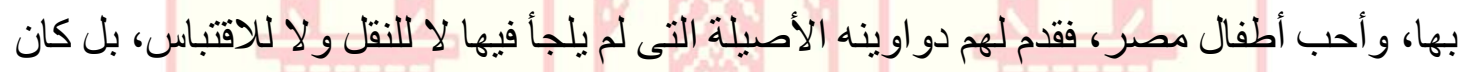

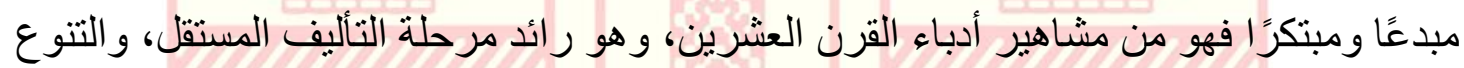

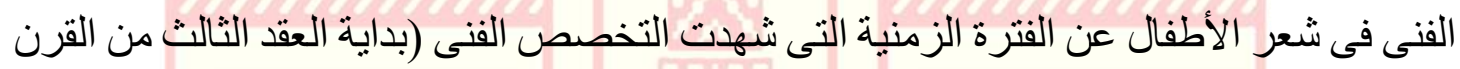

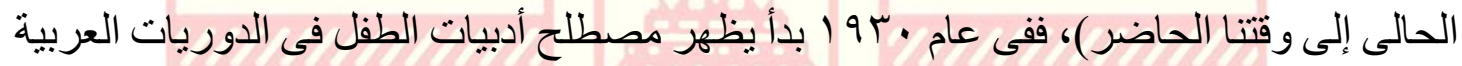

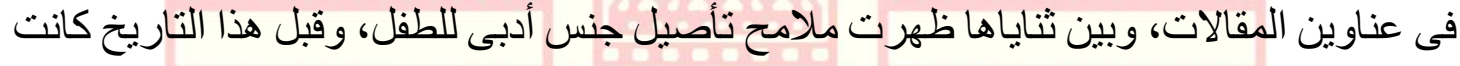

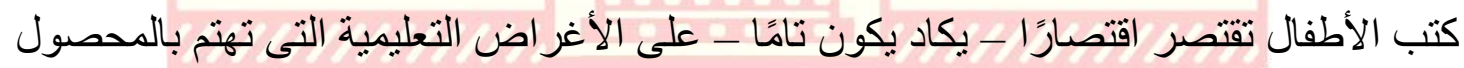

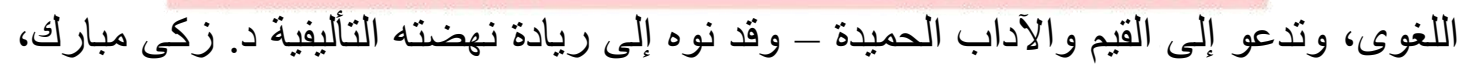

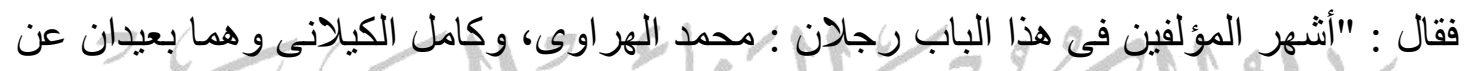

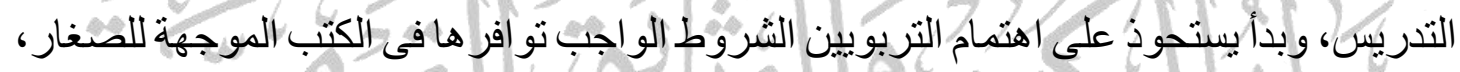

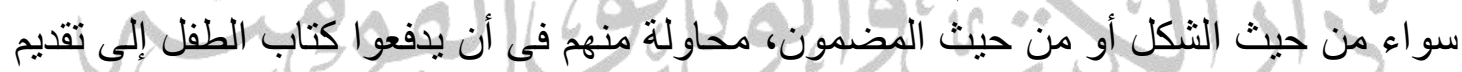

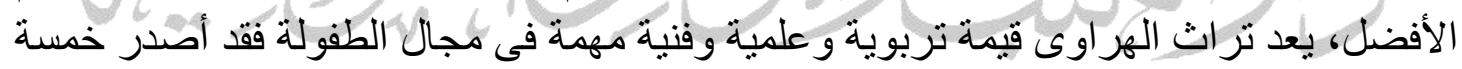

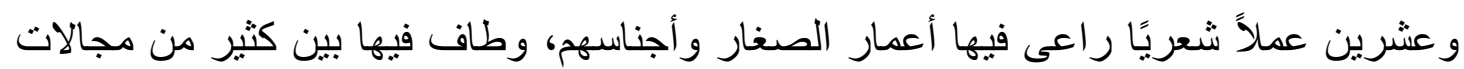

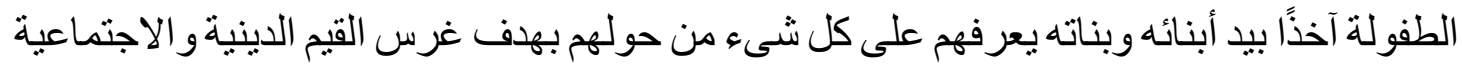
و الخلقية المختلفة إلى جانب المعرفة و الجمال و الدوسيقى جميعًا. 


\section{مولده ونشأته}

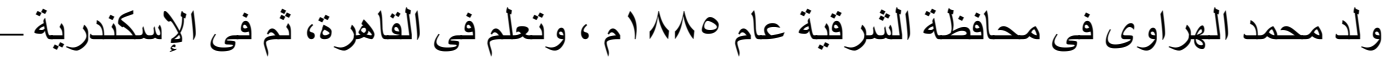

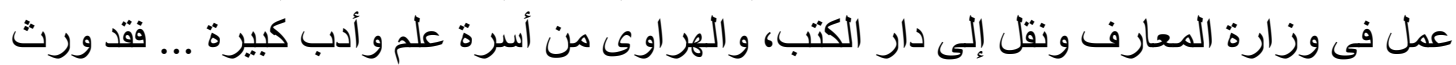

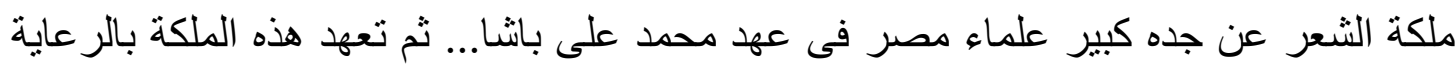

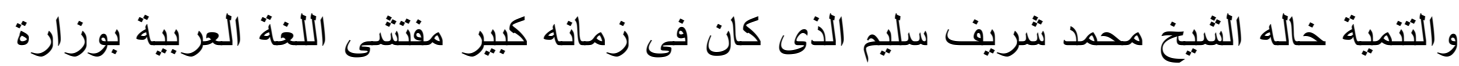

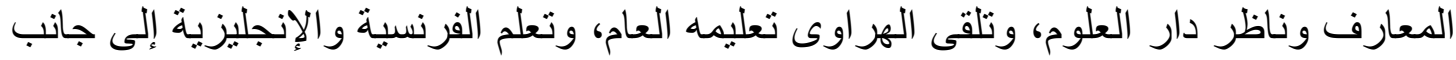

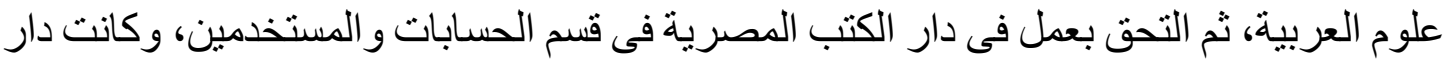

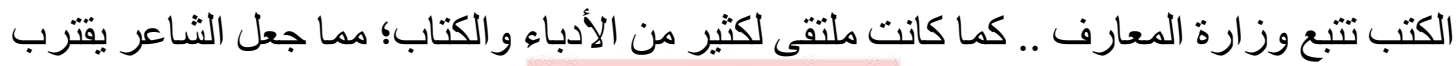

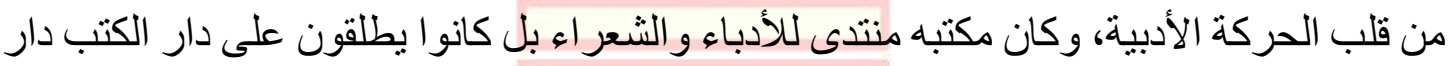

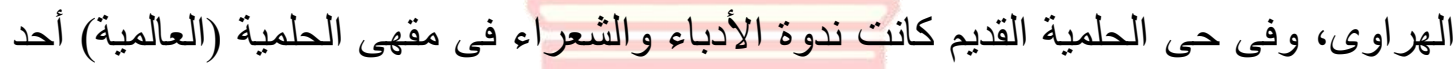

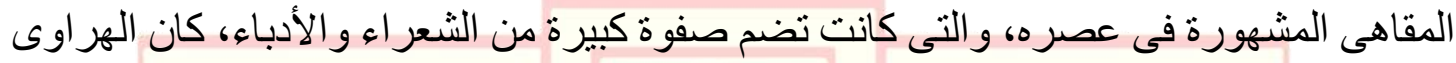

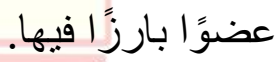

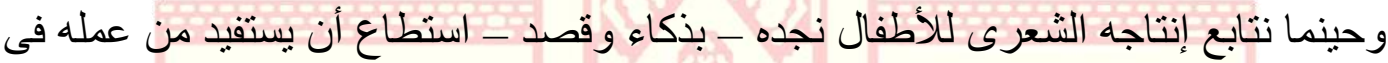

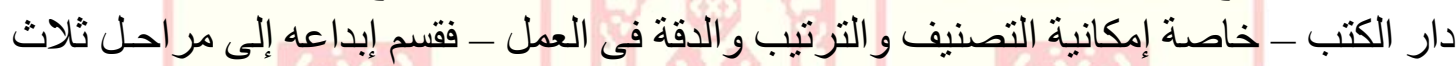

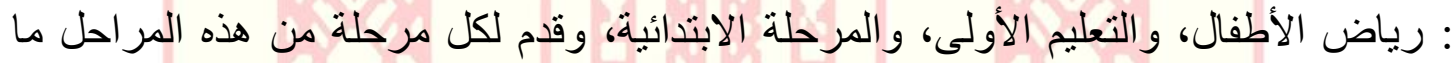

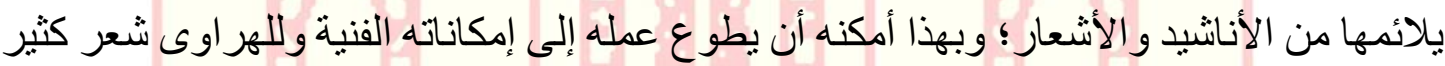

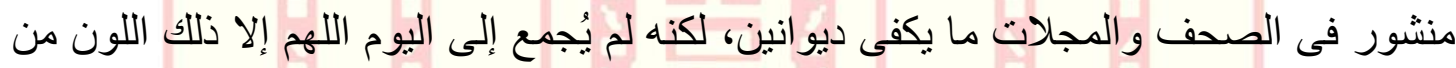

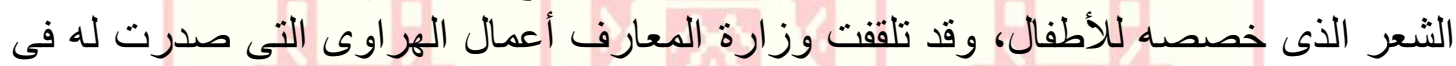
مجال الأطفال، وقررتها على التلاميذ فى مدارسها المختلفة وفى مراحل التعليم الأولى و التعليم

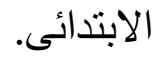

\section{ظواهر فنية فحى شعر الطقولة لمحمد الهراوى}

من يقر أشعر الهر اوى للأطفال بمكنه فى بساطة أن ينبين خصائص شعره الفنية، والتى يمكن

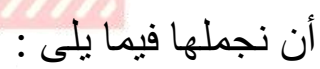

التنوع فى الأغراضن التى تتاولها الثشاعر، مما يدل على ابتكار وتجديد وحسن إحاطة بعالم الطفو لة بمر احلها المتنتالية.

غز ارة الإنتاج الثعرى للأطفال : أودع الشاعر محمد الهراوى مكتبة الأطفال أغزر و أهم

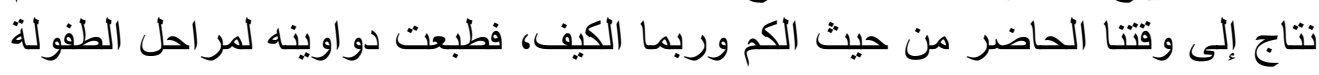

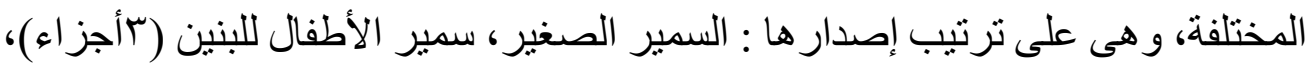

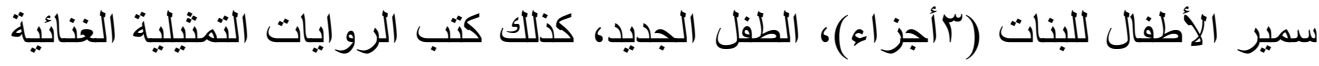

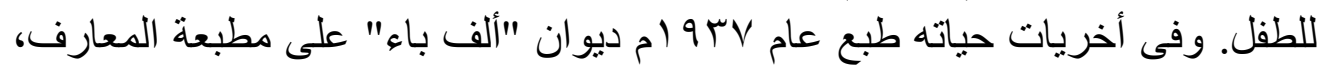

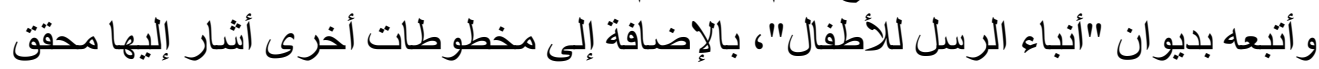

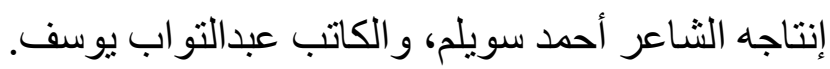


ثبات لغة الأداء الثُعرى : فلم ينزل إلى درك من الإسفاف اللغوى أو الاستعمال الثعبى في الثياء

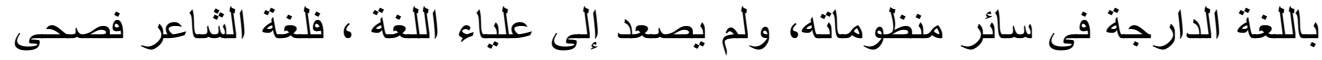
مبسطة، سلسة سليمة.

• بث و إعلاء قيم الحضارة العربية والإسلامية إلى نفوس الصغار : ومن أهم القيم التىى أكد

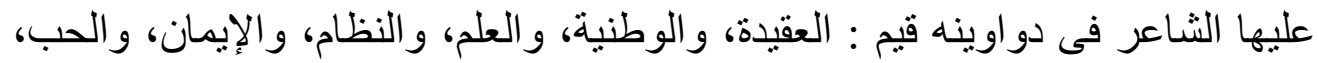

$$
\text { و الانتماء، و الطاعة، و وغير ها من القيم الإيجابية. }
$$

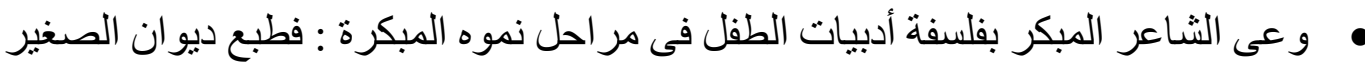

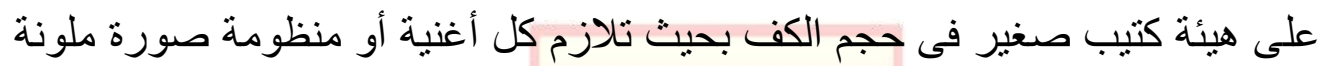
فالطفل يتذوق المحسوس حتى ينتقل إلى التجريد (بالكلمة أو الصورة) ألئ

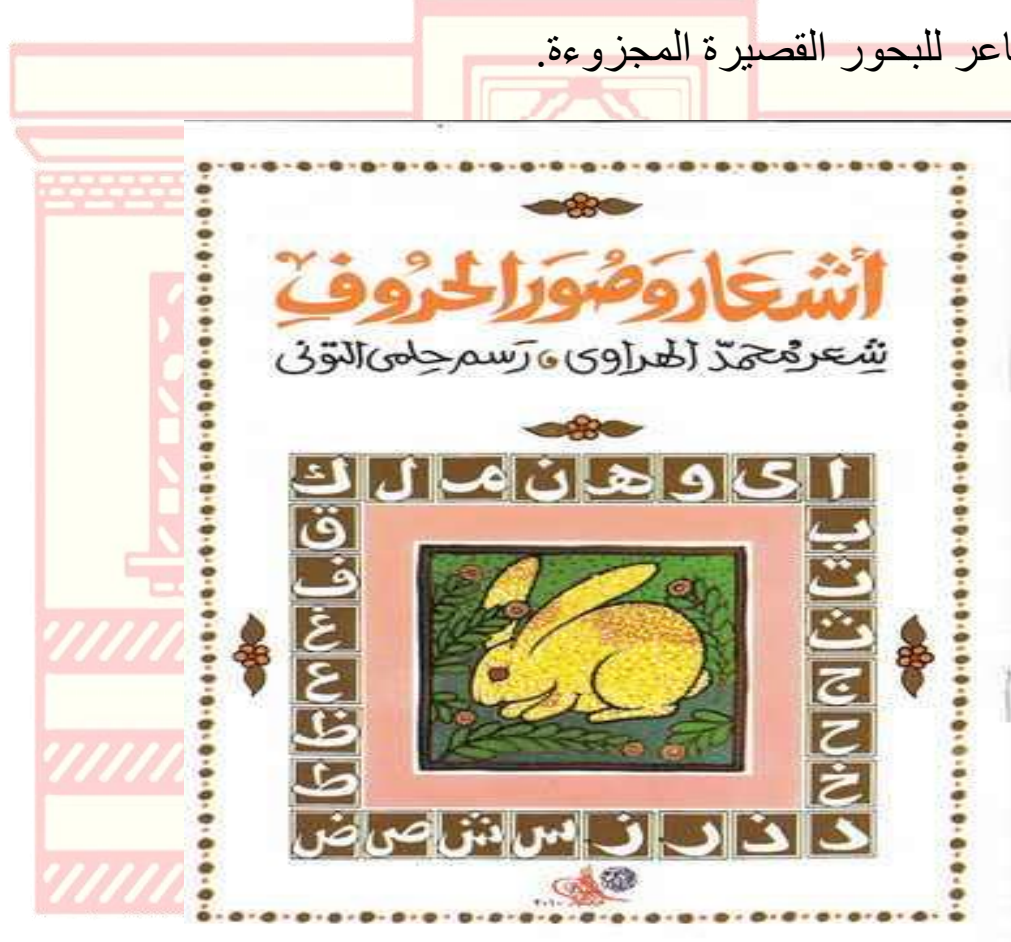

$$
\begin{aligned}
& \text { نماذج من شعر الهراوى } \\
& \text { أولاً : أغانى توقيعية للأطفال } \\
& \text { أنشودة لعب الكرة } \\
& \text { هذى يدى هيا اصعدى } \\
& \text { أنت الكرة كالسكرة } \\
& \text { دورى هنا عندى أنا } \\
& \text { صونى الفما أن يثتما } \\
& \text { حدى إلى نيل العـلا } \\
& \text { لا تلعبى فى المكتب }
\end{aligned}
$$$$
\text { عنى خذى وبى احتذى ستى }
$$$$
\text { لا تهملى فى المنزل }
$$ 
كرتى اسمعى قولى معى مصر اسلمى مصر اغنمى الزمن سامى العلم بين الأمم

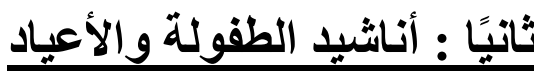

الله جل شأنه له الصفات الباقية رب السماء و الأر اضى و المياه الجارية وربك الذى حباك نعمة و عافية يسمع ما تقو له فى السر و العلانية وييصر النملة فى جنح الليالى الداجية مقتدر ذو رحمة وآخذ بالناصية فخف من الله الذى يعلم كل خافية

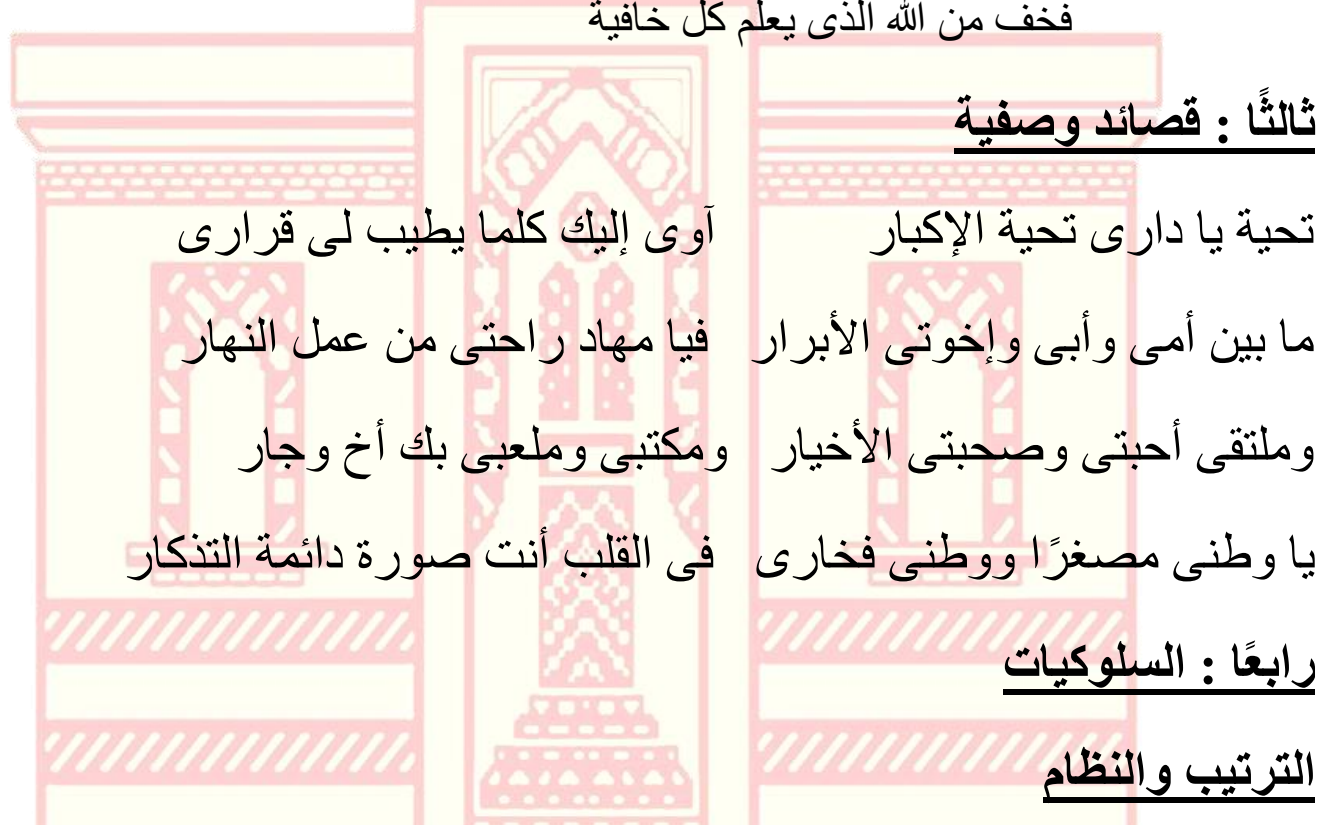
إن الذى يرتب مناعه لا يتعب فكل شئ عنده فى موضع أعده متى يعد إليه يجده في يديه من غير بحث يجهده و لا زمان يفقده حسن نظام العمل يضمن نيل الأمل

إلى جانب الأقاصيص الثعرية، والأناشيد المهنية، والقصص الديفى، والروايات التمثيلية،

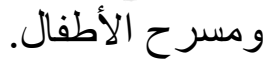
وفاته

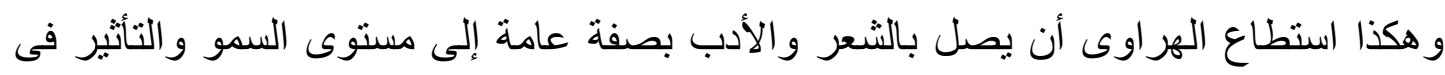

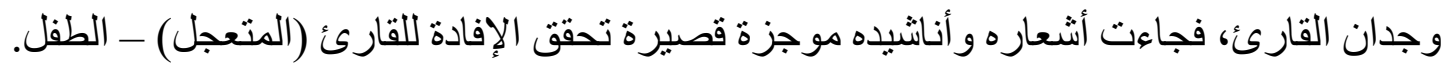

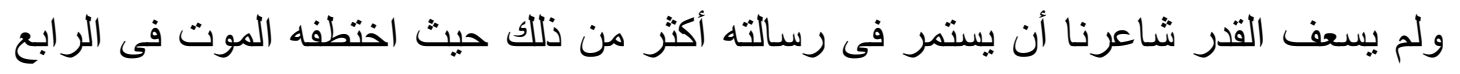
و العشرين من فبر اير عام 9 هو أعن أربعة وخمسين عامًا فقط. 